\title{
The Influence of a Eutrophic Lake to the River Downstream: Spatiotemporal Algal Composition Changes and the Driving Factors
}

\section{Qian Yu ${ }^{1}$, Yongcan Chen ${ }^{1}$, Zhaowei Liu ${ }^{1, *}$, Nick van de Giesen ${ }^{2}$ and Dejun Zhu ${ }^{1}$}

1 State Key Laboratory of Hydroscience and Engineering, Tsinghua University, Beijing 100084, China; E-Mails: yqcherie@126.com (Q.Y.); chenyc@mail.tsinghua.edu.cn (Y.C.); zhudejun@tsinghua.edu.cn (D.Z.)

2 Department of Water Management, Faculty of Civil Engineering and Geosciences, Delft University of Technology, PO Box 5048, 2600 GA Delft, The Netherlands;

E-Mail: n.c.vandegiesen@tudelft.nl

* Author to whom correspondence should be addressed; E-Mail: liuzhw@tsinghua.edu.cn; Tel.: +86-10-6277-2255.

Academic Editor: Miklas Scholz

Received: 4 March 2015 / Accepted: 30 April 2015 / Published: 12 May 2015

\begin{abstract}
Algal blooms have been frequently found at the upper reaches of the Tanglang River, which is downstream from the eutrophic Dianchi Lake. The eutrophic lake upstream is considered to be a potential source of phytoplankton, which contributes to the development of harmful algal blooms in the river downstream and can cause many serious problems for the river ecology. However, few studies focused on these kinds of rivers. Therefore, a field observation and laboratory analysis were conducted in this study. The results showed that the Tanglang River was obviously spatially heterogeneous due to the eutrophic Dianchi Lake upstream. The toxic Microcystis from the Dianchi Lake dominated the phytoplankton at the upper reaches, but these were gradually, rather than immediately, replaced by centric diatoms and chlorococalean green algae in the middle and lower reaches. The results of correlation analysis indicated that the changes in hydrodynamic conditions and underwater light intensity accounted for the spatial variations. The differences in the adaptability of different algae to changing aquatic environments explained the spatial variations of phytoplankton abundance. The dominant algae, most of which was from the Dianchi Lake upstream, determined the characteristics of the total abundance at the Tanglang River.
\end{abstract}


Keywords: eutrophication; phytoplankton structures; Microcystis; hydrodynamic conditions; turbidity

\section{Introduction}

Algal blooms have become a frequent sight in the upper reaches of the Tanglang River during the past few years [1]. In high-bloom seasons, the surface blue-green scums can stretch a long distance in the river downstream [1]. This phenomenon is rare elsewhere in rivers because the initial inoculum of phytoplankton at the beginning of rivers is usually small [2]; as a result, most often, blooms occur only in the middle or lower reaches of large, nutrient-rich rivers [3-5]. The cause of this unusual phenomenon is the upstream eutrophic Dianchi Lake, which may supply a large amount of dominant lacustrine algae to the river downstream. Thus, the Dianchi Lake and the Tanglang River constitute a special case of a river downstream from a eutrophic lake. Nevertheless, the Dianchi Lake-to-the Tanglang River system is not unique because all eutrophic lakes and their outflows fall into this category [6], and the water qualities in these rivers downstream are usually poor. However, few studies have been conducted, especially on this special case $[2,6]$.

Eutrophic lake-to-river systems can cause many problems for society as well as the downstream environment. First, the smelly surface scums might decrease the recreational use of rivers [7]. Moreover, some Cyanobacteria can be toxic, and this includes Microcystis, which is also the main constituent algae found in the Dianchi Lake. The contaminated river water cannot be used directly. This can lead to drinking water crises [8] and water shortages for surrounding communities and for industrial and agricultural production [1,9]. In order to prevent and control these aforementioned problems, it is important to estimate the impact of eutrophic lakes on rivers downstream and to identify the driving factors of different algae's growth and loss. Prygiel and Leitão [6] found that Cyanophycean from the reservoir of Val Joly contaminated the River Helpe Majeutr downstream and disappeared within $30 \mathrm{~km}$. However, they did not systematically analyze the reason of these spatial variations in phytoplankton species.

After analyzing the different characteristics of bloom-forming algae in lakes and rivers [10,11], it is found that some Cyanobacteria, i.e., Microcystis, are not adapted to turbulent flows and might be replaced by some fluvial algae, i.e., centric diatoms and chlorococalean green algae $[9,12,13]$ in fast-flowing rivers. Many existing cases have proven that intensified turbulence of water may lead to algae species shift from buoyant Cyanobacteria to sinking Bacillariophyta [14-17]. However, these experiments were conducted in the same aquatic systems (either in lakes or in rivers) rather than in the lake-to-river coupled systems. There is a need to test that if the spatial variations in phytoplankton species exist in the Tanglang River downstream from the highly eutrophic Dianchi Lake. In addition, it is also important to detect the driving factors accounting for these spatial variations.

In the present study, we hypothesized that the abundance of the lacustrine algae from the Dianchi Lake upstream would decrease in the Tanglang River downstream, and they would sustain a long distance rather than disappear immediately. In addition, we also hypothesized that the hydrodynamic condition rather than nutrient levels or water temperature impacted the spatial variations 
in the phytoplankton abundances and compositions in the river downstream from the eutrophic lake. To test the hypotheses, two datasets were included in this study: Dataset1 included information about the entire Pudu Catchment and Dataset2 focused on the upper reaches of the Pudu River, namely the Tanglang River which is directly influenced by the Dianchi Lake upstream. The objectives of this research were: (1) to evaluate the impact of an upstream eutrophic lake on the downstream river in time and space; (2) to distinguish between the rivers found downstream from eutrophic lakes and other rivers without upstream algae sources; and (3) to examine the driving factors of total phytoplankton abundance in the river downstream from a eutrophic lake.

\section{Materials and Methods}

\subsection{Study Area}

The study area consists of the mouth of the Dianchi Lake and the downstream Pudu River (Figure 1). The Dianchi Lake is located on Yunnan-Guizhou Plateau in Southwest China. It covers $308.6 \mathrm{~km}^{2}$ and the average depth is $4.4 \mathrm{~m}$. The lake is one of the most severely polluted lakes in China and is frequently disturbed by Microcystis blooms [18]. The Pudu River downstream (294 km) is mainly composed of two sections: the Tanglang River $(120 \mathrm{~km})$ and the lower Pudu River $(174 \mathrm{~km})$. The Tanglang River is the only downstream outlet for the Dianchi Lake with an average slope of $2 \%$. The lower Pudu River is downstream in the Tanglang River with an average slope of about 6.1\%o. There are two main tributaries flowing into the lower Pudu River, namely the Zhangjiu River and the Xima River. Another large tributary, the Jiulong River first merges with the Xima River and then the rivers flow into the lower Pudu River together. There is a gate between the Dianchi Lake and the Pudu River, called Zhongtan Gate. However, this gate is mainly for controlling water level but not discharges. Hence, it will not influence the outflow from the Dianchi Lake to the Pudu River. The annual average discharge of the Pudu River is $91.2 \mathrm{~m}^{3} / \mathrm{s}$. The subtropical monsoon climate provides the study area relatively constant temperatures throughout the year with an annual mean temperature of about $15^{\circ} \mathrm{C}[19]$.

The Dianchi Lake has been widely investigated before due to the serious nature of the annual Microcystis blooms [18,20,21]. However, the Tanglang River was only sampled once in 1982 for phytoplankton identification by Qian et al. [22], and the entire Pudu River was once studied for pollutant sources identification by Yu et al. [23]. This is the first time that the Dianchi Lake and the Pudu River are being studied together as a whole system.

\subsection{Datasets and Sampling}

A total of nine sampling stations over the entire Pudu River were included in Dataset1 (Figure 1, S1-S9). Among them, three stations were located on the Tanglang River; the other three were located on the lower Pudu River, and the rest were located at the three main tributaries, respectively. The samples were collected on three consecutive days in three representative seasons, namely the rainy season (August to September in 2010), the normal season (November in 2010) and the dry season (March in 2011). 

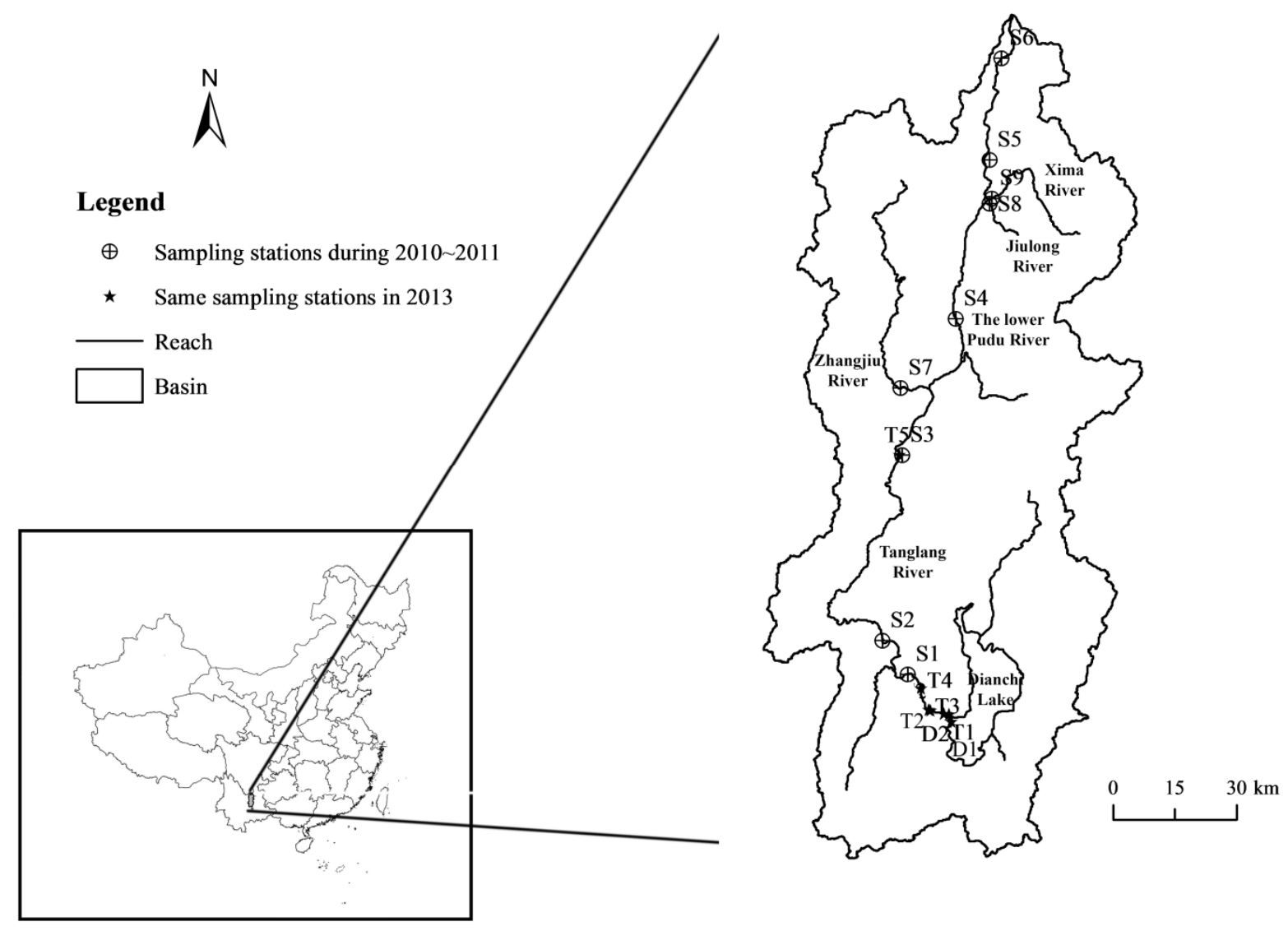

Figure 1. Map of study area and sampling stations in the two datasets.

The samplings included in Dataset 2 were carried out at nine monitoring stations within one day in June 2013 (the rainy season) and at eleven monitoring stations on two consecutive days in September 2013 (the rainy season), respectively. Seven monitoring stations were situated in the same places for both the June and September measurements (Figure 1, D1-D2, and T1-T5). These seven stations included two stations at the mouth of the Dianchi Lake: $-2.04 \mathrm{~km}$ (D1), $0 \mathrm{~km}$ (D2, reference station), and five others along the Tanglang River: $1.47 \mathrm{~km}$ (T1), $4.83 \mathrm{~km}$ (T2), $5.46 \mathrm{~km}$ (T3), $11.38 \mathrm{~km}$ (T4), and $114.60 \mathrm{~km}$ (T5). The samples of surface water $(0.5 \mathrm{~m}$ in depth) were taken from the shore of the lake or the middle of the river. They were preserved in situ with Lugol's iodine solution. The $1 \mathrm{~L}$ water samples taken from each station were transported to the laboratory in darkened bottles. After $24 \mathrm{~h}$ standing in a laboratory, the supernate was siphoned from the samples and $30 \mathrm{~mL}$ of the remaining residue was prepared for further phytoplankton identification.

\subsection{Phytoplankton Data and Environmental Variables}

In Dataset1, eleven environmental parameters were determined according to State Environmental Protection Administration (SEPA) standard methods [24]. They were water temperature (WT), $\mathrm{pH}$, suspended solids (SS), dissolved oxygen (DO), chemical oxygen demand by the potassium permanganate method (CODMn), chemical oxygen demand (COD), 5-day biochemical oxygen demand $\left(\mathrm{BOD}_{5}\right)$, ammonia nitrogen $\left(\mathrm{NH}_{3}-\mathrm{N}\right)$, total phosphorus (TP), total nitrogen (TN) and chlorophyll-a (Chla). In this dataset, Chla was regarded as a proxy of the phytoplankton biomass. In Dataset2, eight environmental variables and phytoplankton species were determined. The environmental parameters 
were only detected in September. WT and turbidity were measured in situ at all eleven stations in September 2013 using YSI 6600 (Yellow Spring Instruments, Yellow Springs, OH, USA), a multiparameter water quality sonde. The DO was detected in situ by YSI PRO-ODO, a dissolved oxygen meter. TN, TP, orthophosphate $\left(\mathrm{PO}_{4}{ }^{3-}\right)$ and dissolved silicon ( $\mathrm{Si}$ ) were examined in the laboratory followed SEPA [24]. The time of travel (TT) was also introduced to characterize the movement of phytoplankton in the Tanglang River. Different from completely mixed in lakes, phytoplankton pass through rivers as a plug [2]. In this study, we simply represented TT as the ratio of the reach lengths and the average velocities of the reach in the Tanglang River. The surface velocity of water was measured in situ by LS300 (Nanjing Sheng Rong equipment limited company, Nanjing, China), a portable flow meter. Phytoplankton species were identified and counted at species level by using a Nikon E100 (Sendai, Japan) biological microscope $(10 \times 40)$ according to phytoplankton morphology [25]. Species with filamentous and colonial forms were counted at the cell level.

\subsection{Statistical Analysis}

We performed the Q-style hierarchical Cluster Analysis (CA) and Pearson correlation analysis using SPSS 20.0 to determine the spatial differences of sampling stations and the driving factors of different algae, respectively. The Q-style hierarchical CA is a multivariate method to cluster similar samples into one cluster based on the characteristics of objects $[23,26]$. The similarity is measured by Euclidean distance using Ward's method based on normalized data [27]. In these cases, by means of the Q-style hierarchical CA, nine spatial stations located along the Pudu River were divided into specific-numbered groups based on the similarity of 11 environmental variables in Dataset1. The results of the Q-style CA can help to discriminate the spatial differences. The Pearson correlation was first used to detect the differences among site clusters in Dataset1 and then used in Dataset2 to study the driving factors of different phytoplankton phyla.

\section{Results}

\subsection{Physical and Chemical Variables}

In Dataset1 (Table 1), the highest WT in the Pudu River was observed in August (September) 2010 with an average temperature of $22.16{ }^{\circ} \mathrm{C}$ and this temperature was 6.8 and $7.4{ }^{\circ} \mathrm{C}$ higher than the temperatures measured in March 2011 and November 2010, respectively. The temperature stayed stable in the space. The $\mathrm{pH}$ was always higher than 7 and lower than 9. The highest concentration of $\mathrm{TN}$ appeared in March 2011. The concentration variations of $\mathrm{NH}_{3}-\mathrm{N}$ were not consistent with $\mathrm{TN}$. The concentrations of TP were much higher in November than in March or August (September).

In Dataset2 (Table 1), the WT in the Dianchi Lake varied little from the WT in the Tanglang River downstream. This was similar with the findings in Dataset1. The average temperature in June 2013 $\left(26.79{ }^{\circ} \mathrm{C}\right)$ was about $4.22^{\circ} \mathrm{C}$ higher than that in September $2013\left(22.57{ }^{\circ} \mathrm{C}\right)$. Nutrient concentrations were very high at all stations in September. The concentrations of TN ranged from 4.31 to $31.85 \mathrm{mg} / \mathrm{L}$, while those of TP ranged from 0.22 to $2.92 \mathrm{mg} / \mathrm{L}$. Both the levels of TP and $\mathrm{PO}_{4}{ }^{3-}$ increased rapidly in the middle reaches of the Tanglang River after a long period of stabilization in the upper reaches of the river. However, these then dramatically decreased in the lower reaches of the Tanglang River. $\mathrm{PO}_{4}{ }^{3-}$ 
was significantly correlated with TP $(R=0.772, P<0.01)$. The concentrations of Si ranged from 0.2 to $4.06 \mathrm{mg} / \mathrm{L}$. The lowest concentration was found in the mouth of the Dianchi Lake with the concentrations increasing along the river. The turbidity maintained at high values $(>53.7 \mathrm{NTU}+)$ and showed no obvious trend in the longitudinal. The velocity (Figure 2) and the TT increased significantly in the river downstream and reached the high values at T5, $1.5 \mathrm{~m} / \mathrm{s}$ and 1.557 days (d), respectively. The spatial increasing variations in velocities were the most obvious among all the factors.

Table 1. Mean and range of environmental parameters in Dataset1 and Dataset2.

\begin{tabular}{|c|c|c|c|c|c|}
\hline Dataset & Parameters & Unit & Mean & Range & No. \\
\hline \multirow{11}{*}{$\begin{array}{l}\text { Dataset1 (9 stations spread over the } \\
\text { entire Pudu River in August } \\
\text { (September) and November 2010, } \\
\text { March 2011) }\end{array}$} & WT & ${ }^{\circ} \mathrm{C}$ & 17.49 & 12.8 (Mar.)-24.0 (Sept.) & 81 \\
\hline & $\mathrm{pH}$ & - & 7.56 & 6.4 (Nov.)-8.6 (Mar.) & 81 \\
\hline & SS & $\mathrm{mg} / \mathrm{L}$ & 71.85 & 35 (Nov.)-120 (Mar.) & 81 \\
\hline & DO & $\mathrm{mg} / \mathrm{L}$ & 7.60 & 3.6 (Aug.)-13.0 (Sept.) & 81 \\
\hline & $\mathrm{COD}_{\mathrm{Mn}}$ & $\mathrm{mg} / \mathrm{L}$ & 3.98 & 1.05 (Aug.)-8.48 (Mar.) & 81 \\
\hline & $\mathrm{COD}_{\mathrm{Cr}}$ & $\mathrm{mg} / \mathrm{L}$ & 27.39 & 7.2 (Mar.)-57.0 (Mar.) & 81 \\
\hline & $\mathrm{BOD}_{5}$ & $\mathrm{mg} / \mathrm{L}$ & 4.29 & 0.5 (Sept.)-13.0 (Sept.) & 81 \\
\hline & $\mathrm{NH}_{3}-\mathrm{N}$ & $\mathrm{mg} / \mathrm{L}$ & 1.73 & 0.137 (Sept.)-5.360 (Mar.) & 81 \\
\hline & $\mathrm{TP}$ & $\mathrm{mg} / \mathrm{L}$ & 0.49 & 0.017 (Mar.)-4.008 (Nov.) & 81 \\
\hline & $\mathrm{TN}$ & $\mathrm{mg} / \mathrm{L}$ & 3.70 & 0.516 (Sept.)-10.110 (Mar.) & 81 \\
\hline & Chla & $\mathrm{mg} / \mathrm{L}$ & 4.64 & 0.3 (Nov.)-28.5 (Mar.) & 81 \\
\hline \multirow{10}{*}{$\begin{array}{l}\text { Dataset2 (11 stations spread over the } \\
\text { Tanglang River in September 2013) }\end{array}$} & WT & ${ }^{\circ} \mathrm{C}$ & 22.04 & $20.66(\mathrm{~T} 2-8)-23.32(\mathrm{D} 2)$ & 11 \\
\hline & Length & $\mathrm{km}$ & 35.80 & $-2.04(\mathrm{D} 1)-114.60(\mathrm{~T} 5)$ & 11 \\
\hline & Turbidity & NTU+ & 80.45 & 53.7 (T2-4)-185.4 (T4) & 11 \\
\hline & Velocity & $\mathrm{m} / \mathrm{s}$ & 0.54 & $0.05(\mathrm{~T} 1)-1.556(\mathrm{~T} 2-6)$ & $10^{\mathrm{a}}$ \\
\hline & TT & $\mathrm{d}$ & 0.42 & $0.339(\mathrm{~T} 1)-1.557$ (T5) & $9^{b}$ \\
\hline & DO & $\mathrm{mg} / \mathrm{L}$ & 8.08 & $4.13(\mathrm{~T} 2-6)-13.22(\mathrm{D} 2)$ & 11 \\
\hline & TP & $\mathrm{mg} / \mathrm{L}$ & 1.05 & $0.22(\mathrm{D} 2)-2.92(\mathrm{~T} 4)$ & 11 \\
\hline & $\mathrm{TN}$ & $\mathrm{mg} / \mathrm{L}$ & 12.10 & $4.31(\mathrm{~T} 2-6)-31.85(\mathrm{~T} 2-7)$ & 11 \\
\hline & $\mathrm{PO}_{4}^{3-}$ & $\mathrm{mg} / \mathrm{L}$ & 0.41 & $0.084(\mathrm{~T} 2)-1.44(\mathrm{~T} 2-7)$ & 11 \\
\hline & $\mathrm{Si}$ & $\mathrm{mg} / \mathrm{L}$ & 1.74 & $0.2(\mathrm{D} 1)-4.06(\mathrm{~T} 2-8)$ & 11 \\
\hline
\end{tabular}

Notes: The month of the lowest (highest) value in Dataset1 is indicated in brackets. The sampling station in September 2013 of the lowest (highest) value in Dataset2 is indicated in the brackets as well. T2-4, T2-6, T2-7 and T2-8 were the other four sampling stations in September 2013, which are not discussed in this paper because they are not located in the same places as the sampling stations in June. The increasing number indicates the longer distance from D2. ${ }^{a}$ Velocity was detected in situ from D2 to T9 in September 2013; $\mathrm{b}$ The time of travel at the mouth of the Dianchi Lake (D1 and D2) was not calculated due to the calculation method of TT being only applicable to plug flow in the river; ${ }^{c}$ The environmental variables at all eleven sampling stations in September 2013 were determined. Among the eleven stations, seven of them were located in the same places with the stations in June 2013. Hence, we only compared the temporal and spatial variations in phytoplankton abundance at the same seven stations. However, when the relationships between the abundance and environmental variables in September were studied, we considered all eleven pieces of data. 


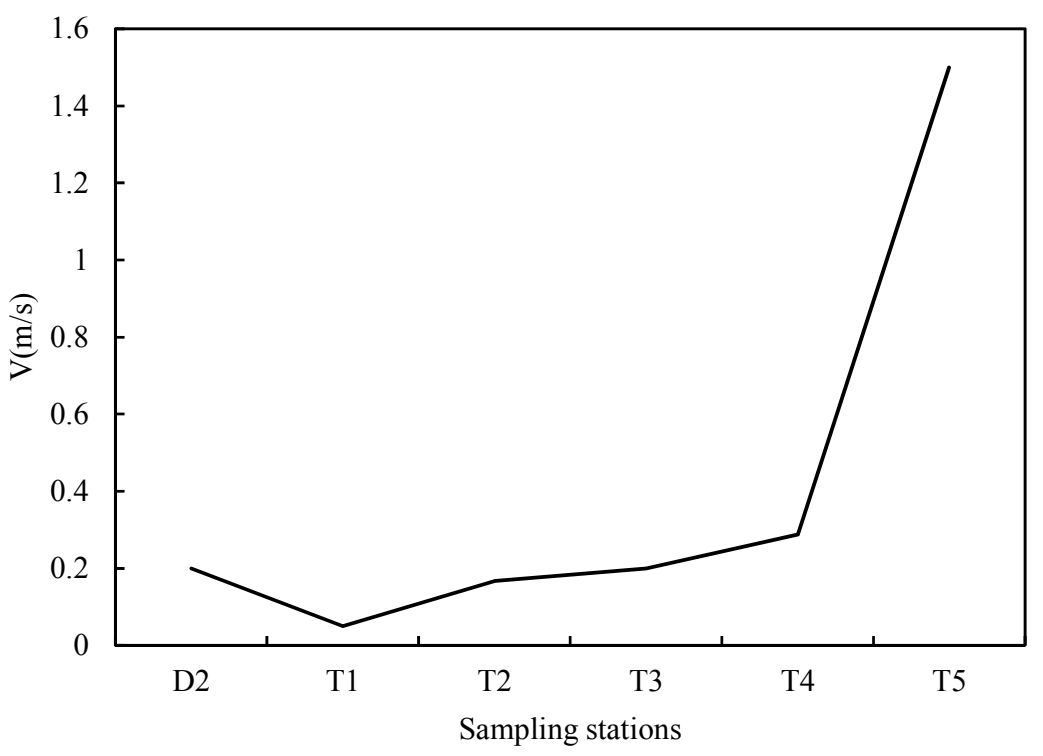

Figure 2. The velocities in the same seven sampling stations in September 2013.

\subsection{Spatial Site Grouping Based on Environmental Variables}

According to Dataset1, we partitioned the nine stations into three and five groups based on eleven physicochemical parameters, respectively. As shown in Table 2 (three clusters), the classifications were not consistent throughout the three typical seasons, but they showed similar trends. In general, the three stations situated along the Tanglang River (S1-S3) belonged to one group (C1), the three stations located on the lower Pudu River (S4-S6) were clustered into the same spatial cluster (C2) and the three monitoring stations at the three tributaries (S7-S9) were identified as another group (C3). We found that these three spatial clusters were representative of three different river types. $\mathrm{C} 1$ represents a river downstream from a eutrophic lake that is directly influenced by the lacustrine algae flowing from the lake. $\mathrm{C} 2$ represents a river influenced by the flow of the river upstream together with other tributaries. C3 represents rivers without upstream eutrophic lakes. However, when the nine stations were classified into five groups (Table 2), the three stations within $\mathrm{C} 1$ were distributed into three different groups for both the dry season and the rainy season. In contrast, the other stations within $\mathrm{C} 2$ and $\mathrm{C} 3$ remained in the same clusters without changes. This classification revealed more distinct differences among three stations within $\mathrm{C} 1$ compared to other stations within $\mathrm{C} 2$ and $\mathrm{C} 3$. Moreover, the correlations between TP and Chla in $\mathrm{C} 1, \mathrm{C} 2$ and $\mathrm{C} 3$ were $0.074,-0.462(P<0.05)$ and 0.518 $(P<0.01)$, respectively. These different correlations showed the different characteristics of the three various spatial clusters to some extent. TP was found to be significantly positively related to the total biomass in tributaries (C3) while weakly correlated with the biomass in the Tanglang River (C1). 
Table 2. Site grouping according to Q-style Cluster Analysis (CA) based on Dataset1 (The sites with the same number were gathered into the same cluster).

\begin{tabular}{cccccccc}
\hline \multirow{2}{*}{ Sites } & \multicolumn{3}{c}{ Three Clusters } & & \multicolumn{3}{c}{ Five Clusters } \\
\cline { 2 - 3 } \cline { 6 - 7 } \cline { 6 - 7 } & Dry Season & Normal Season & Rainy Season & & Dry Season & Normal Season & Rainy Season \\
\hline S1 & 1 & 1 & 1 & & 1 & 1 & 1 \\
S2 & 1 & 1 & 1 & & 2 & 1 & 2 \\
S3 & 1 & 1 & 2 & & 3 & 2 & 3 \\
S4 & 2 & 1 & 3 & & 4 & 2 & 4 \\
S5 & 2 & 1 & 3 & & 4 & 3 & 4 \\
S6 & 2 & 1 & 3 & & 4 & 2 & 3 \\
S7 & 3 & 2 & 2 & & 5 & 4 & 5 \\
S8 & 3 & 3 & 3 & & 5 & 5 & 3 \\
S9 & 3 & 3 & 2 & 5 & 5 & 4 \\
\hline
\end{tabular}

\subsection{Spatial and Temporal Phytoplankton Compositions}

All of the samples involved in Dataset2 in this study were characterized by high abundances (above $10^{8}$ cells $/ \mathrm{L}$ ). The highest abundance was observed at the monitoring stations situated in the Dianchi Lake with the level of abundance decreasing further downstream in the river (Figure 3). The compositions of phytoplankton in the Dianchi Lake-to-the Tanglang River system were similar in June and September 2013. The spatial variations were more obvious than temporal variations. A total of $90+$ species were identified in June and 100+ species were identified in September, which belonged to seven different phyla. The symbol of + was used to show that more than one species were found, but could not been identified. Bacillariophyta (diatoms) contributed the most species (36 in June and 39 in September), followed by Chlorophyta (green algae, 24+ and 25+), Cyanobacteria (19+ and 26), Xanthophyta (3 and 3), Euglenophyta (5 and 2), Dinophyta (dinoflagellates, 1 and 4) and Cryptophyta (2 and 1). Among them, Cyanobacteria contributed the most to the total abundance, followed by Chlorophyta and Bacillariophyta. These three phyla made up more than $98 \%$ of the total abundance at all stations in June and September, except for station T5 where the phyla made up $86 \%$ of the total abundance in June (Figure 3). Cyanobacteria dominated the Dianchi Lake and then entrained within the outflow directly entered the Tanglang River. They made up $85 \%$ of the total abundance at all sampling stations in September and almost all stations in June except T5 (Figure 3). Microcystis was the main genus of Cyanobacteria at almost all stations. The correlations between the abundance of Microcystis and that of Cyanobacteria in June and September were $0.726(P<0.05)$ and 0.993 $(P<0.01)$, respectively. Cyanobacteria lost their leading position in relation to the disappearance of Microcystis at T5 in June. Due to the low percentage of Cyanobacteria at T5 in June (3.3\%), Chlorophyta (56.3\%) and Bacillariophyta (27.1\%) dominated this station. Along the Tanglang River, the percentage of Cyanobacteria decreased quickly within $28 \mathrm{~km}$ away from the Dianchi Lake in June and then declined more gradually. The percentage of Chlorophyta increased dramatically within $28 \mathrm{~km}$ away from the Dianchi Lake and then softened, while the proportion of Bacillariophyta continued rising (Figure 4). The abundance of Microcystis in the Tanglang River decreased exponentially while the abundances of centric diatoms and chlorococcales green algae increased both in June and September. 

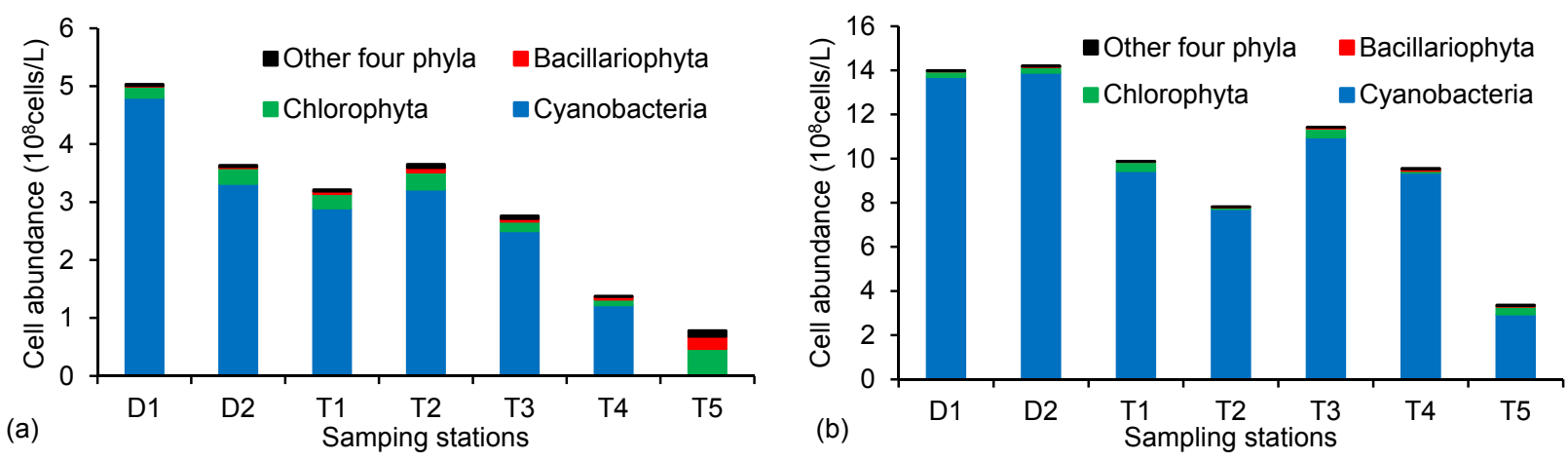

Figure 3. The phytoplankton compositions at the same seven stations (a) in June (b) in September (Other four phyla: Xanthophyta, Euglenophyta, Dinophyta and Cryptophyta).

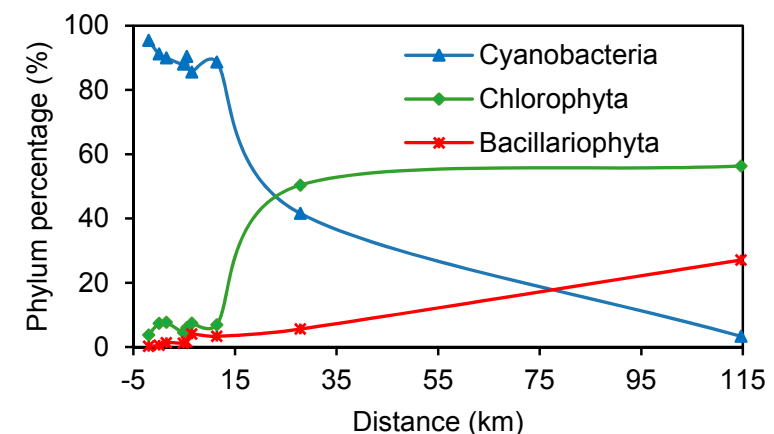

(a)

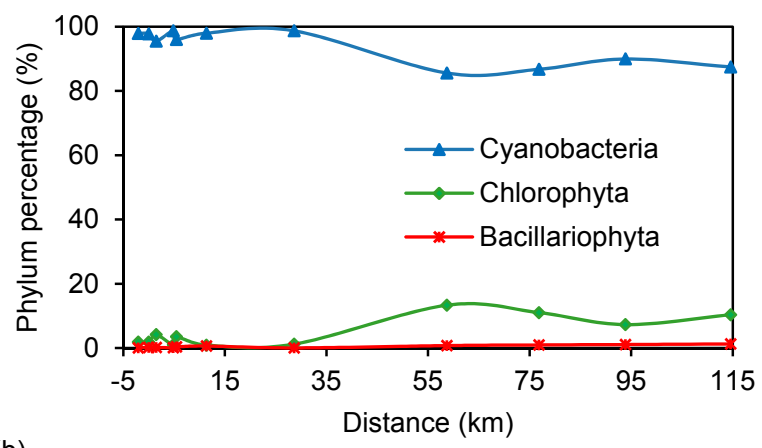

(b)

Figure 4. The trends of three main phytoplankton phyla in the Dianchi Lake-to-the Tanglang River (a) in June according to samplings at nine sampling stations (b) in September according to samplings at eleven sampling stations.

Seasonal variations in the abundances were distinct in this study (Figure 5). The total abundance recorded in September was almost two times higher than that in June. The abundance of Cyanobacteria entering the Tanglang River at T1 was $9.44 \times 10^{8}$ cells/L in September, which was two times greater than the corresponding measurement of $2.89 \times 10^{8}$ cells/L in June (Figure 5). In June, the percentage of Microcystis decreased from $84.3 \%$ at D2 to $64.6 \%$ at T3 to 0 at T5. In September, the percentage of Microcystis at D2 was $80.66 \%$, similar to that in June. However, the percentage increased a little at T3 after a mild decrease at T1. Moreover, the percentage still remained around $77.5 \%$ at $\mathrm{T} 5$, which was different from the measurements in June. Unlike Cyanobacteria, the total abundance of other algae at $\mathrm{T} 1$ was $4.47 \times 10^{7}$ cells $/ \mathrm{L}$ in September, which was similar to the $3.22 \times 10^{7}$ cells/ $\mathrm{L}$ recorded in June (Figure 5). However, the spatial variations in the abundances of three main phyla were not as obvious in September as they were in June (Figure 4). Nevertheless, we still found that the percentage of Cyanobacteria decreased downstream in the river, while that of Chlorophyta and Bacillariophyta increased (Figure 4). In June, the Cyanobacteria abundance at T5 decreased by $99.2 \%$ in comparison to that at D2, the Chlorophyta abundance at T5 increased by $64.8 \%$ compared to that at D2 and the Bacillariophyta abundance at T5 increased by $378.7 \%$ compared with that at D2 (Figure 4). In September, the corresponding values were $78.8 \%, 31.0 \%$ and $73.5 \%$, respectively (Figure 4). 
In spite of differences in abundances, the phytoplankton compositions in the Tanglang River were similar in June and September.
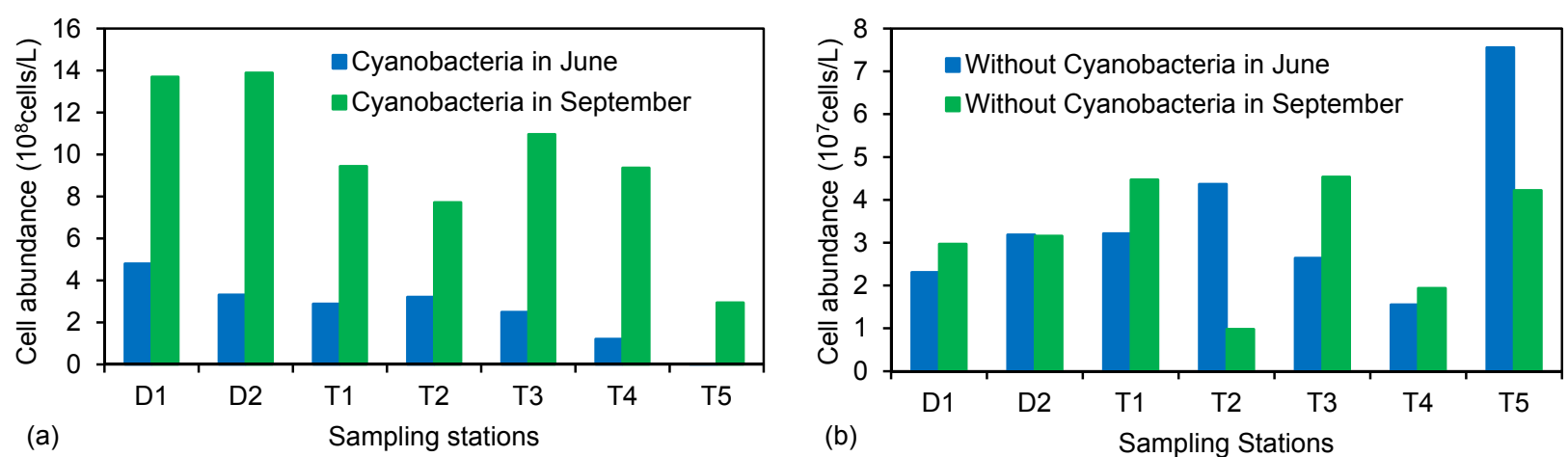

Figure 5. Comparisons between (a) the abundance of Cyanobacteria in June and in September and (b) the abundance without Cyanobacteria in June and in September.

\subsection{Relationships between Phytoplankton Abundance and Environmental Variables in the Dianchi} Lake-to-the Tanglang River in September 2013

The most influential factors on the total abundance and three main phyla in September were different. Due to the high correlation $(R=0.999, P<0.01)$ between Cyanobacteria abundance and the total abundance, the driving factors of the total abundance were similar to those of the Cyanobacteria. According to Table 3, Cyanobacteria abundance was negatively correlated with all the nutrients, including TN, TP, $\mathrm{PO}_{4}{ }^{3-}$ and $\mathrm{Si}$. The abundances of green algae and diatoms were weakly related with these nutrients. In addition, the abundances of main phytoplankton were not significantly related with WT. The abundance of Cyanobacteria was significantly negatively related with the reach lengths $(R=-0.696, P<0.05)$ and the TT $(R=-0.617, P<0.05)$. Although the correlations were not significant, both Chlorophyta abundance $(R=0.248, R=0.044)$ and Bacillariophyta abundance ( $R=0.370, R=0.331)$ were positively correlated with the reach lengths and the TT. The velocity inhibited the abundance of Cyanobacteria $(R=-0.186)$ but encouraged the abundances of green algae $(R=0.564)$ and diatoms $(R=0.297)$. Moreover, Cyanobacteria abundance was positively related with the turbidity $(R=0.638)$, while Bacillariophyta were negatively related to the turbidity $(R=-0.412)$.

Table 3. Pearson correlation coefficients between variables and phytoplankton abundances in September 2013.

\begin{tabular}{|c|c|c|c|c|c|c|c|c|c|c|}
\hline Abundance & Length & Velocity & TT & WT & Turbidity & DO & $\mathbf{T N}$ & TP & $\mathrm{PO}_{4}{ }^{3-}$ & $\mathbf{S i}$ \\
\hline Total abundance & $-0.690 *$ & -0.163 & $-0.619 *$ & 0.544 & 0.652 & 0.273 & -0.165 & 0.008 & -0.502 & -0.586 \\
\hline Cyanobacteria & $-0.696 *$ & -0.186 & $-0.617 *$ & 0.556 & 0.638 & 0.294 & -0.161 & -0.003 & -0.516 & -0.593 \\
\hline Chlorophyta & 0.248 & 0.564 & 0.044 & -0.366 & 0.229 & -0.521 & -0.043 & 0.254 & 0.418 & 0.253 \\
\hline Bacillariophyta & 0.370 & 0.297 & 0.331 & -0.362 & -0.412 & -0.229 & -0.262 & -0.053 & 0.235 & 0.350 \\
\hline Microcystis & $-0.677 *$ & -0.141 & -0.585 & 0.510 & $0.654 *$ & -0.234 & -0.164 & 0.023 & -0.509 & -0.573 \\
\hline
\end{tabular}




\section{Discussion}

\subsection{The Influence of an Upstream Eutrophic Lake on Temporal and Spatial Phytoplankton Composition Variations in the River Downstream}

Shallow lakes at low latitudes usually succumb to single species blooms, especially Microcystis (one of the toxic Cyanobacteria) [28]. These blooms are not only tolerant to higher insolation, but they also grow better at higher temperatures [29,30]. Therefore, Cyanobacterial blooms threaten George Lake in Uganda [29], as well as Taihu Lake [8] and Dianchi Lake [31] in China on a frequent basis. The year-round warm temperatures at the Dianchi Lake have lengthened the optimal periods for Microcystis blooms compared to other lakes. The stable aquatic conditions, suitable temperatures and sufficient nutrients create the proper environment for Microcystis to grow [32] in the Dianchi Lake. The main difference between the measurements in June and September was the quantity of the Microcystis. Since most of the phytoplankton in the upper reaches of the Tanglang River came from the Dianchi Lake upstream, the phytoplankton structures were similar in June and September. The big difference in the abundance of Microcystis from the Dianchi Lake upstream determined the variations downstream. Considering that the abundance of the Microcystis in June in the Dianchi Lake was much smaller than that in September, the abundance of the Microcystis in June $\left(2.47 \times 10^{8}\right.$ cells/L at T1) in the Tanglang River was also much smaller than that in September $\left(7.95 \times 10^{8}\right.$ cells/L at T1). However, the decrease rate of the Microcystis in June was larger than that in September. The cause of this phenomenon might be the discharges. The average discharge in June is about $112 \mathrm{~m}^{3} / \mathrm{s}$ while the average discharge in September is about $200 \mathrm{~m}^{3} / \mathrm{s}$. The smaller discharge in June means that the TT in the Tanglang River might be longer than that in September. In this case, a large sum of the Microcystis in June would be lost due to longer transport time. However, a large amount of the Microcystis in September would be transported downstream rather than be lost otherwise. Therefore, the Microcystis would decrease much more in June within the same distance in the Tanglang River, as compared to September.

We regarded Microcystis as representative of the Dianchi Lake in this study due to their rare occurrence in rivers [1]. The percentage of the Microcystis abundance recorded at the different stations may reflect the impact of the Dianchi Lake. Unlike in the rivers without eutrophic lakes upstream where the maximum abundance occurs in the middle reaches [33] with centric diatoms dominating [3] or in the lower reaches with potamoplankton such as chlorococcalean colonial greens dominating [4], Microcystis dominated the upper and middle reaches of the Tanglang River with the total abundance declining downstream in the river. The influence of the Dianchi Lake was significant on the upper reaches of the Tanglang River, but the impact lessened further away from the lake as Microcystis abundance decreased. The spatial variations of the decrease in the Microcystis and the increase in green algae and diatoms accounted for the distinct differences among the three stations in site cluster $\mathrm{C} 1$ over space. In addition, the characteristics of C3 (tributaries) and C1 (rivers affected by the eutrophic lake upstream directly) were completely different. The total abundance was significantly positively related with TP in C3 because the growth of algae in $\mathrm{C} 3$ required nutrients and the level of TP increased as the algae abundance increased [34]. However, the total abundance was not correlated with $\mathrm{TP}$ at all in $\mathrm{C} 1$ because most of the algae in $\mathrm{C} 1$ were from the Dianchi Lake upstream. Even though some fluvial algae in $\mathrm{C} 1$ needed nutrients to grow, the decay of lacustrine algae does 
release nutrients [34]. Hence, the relationship between the total abundance and nutrients in $\mathrm{C} 1$ (the Tanglang River) was more complicated. With more turbulent flow in the middle and the lower reaches of the Tanglang River, the Microcystis from the Dianchi Lake were not able to adapt to the river's aquatic environment [15] and thus the abundance of Microcystis obviously declined. Consequently, the other competitor algae could obtain the extra resources necessary to grow. Hence, Cyanobacteria were gradually replaced by Chlorophyta and Bacillariophyta in the lower Tanglang River.

\subsection{Impacts of Environmental Variables on the Spatial Phytoplankton Variations}

When we consider the large number of studies on eutrophication in lakes and the distinct characteristics between rivers and lakes, we find several possible driving factors that can influence algae growth in rivers including the level of nutrients, the temperature level, incident light intensities and hydrological conditions $[1,2,35]$. In the river downstream from a lake, the biggest difference between the lacustrine ecosystem and the riverine ecosystem might be the main reason for the phytoplankton variations in the space. In this case, the significant change in hydrodynamic conditions was an important factor [36] as velocities had the most apparent variations from the Dianchi Lake to the Tanglang River downstream in comparison to other physical or chemical factors. Levels of nutrients and WT were not responsible for spatial phytoplankton variations in nutrient-rich lake-to-river systems. Moreover, unlike in lakes, the grazing pressure in rivers is not that important [1] due to the limited number of survivable predators. Only fast-growing aquatic organisms (such as rotifers) that commonly have low filtering rates can live in turbulent rivers [11,37]. The characteristics of the dominant algae may determine the characteristics of the total abundance. Therefore, in the Tanglang River, the total abundance was influenced by the driving factors of Cyanobacteria.

The level of nutrients was not a limiting factor in this study. $\mathrm{P}$ as a limiting factor in fresh lakes is widely accepted by researchers [38] while its role as a limiting nutrient in rivers is still unsettled [2]. In this combined system, the limiting nutrient found in upstream lakes may significantly affect rivers downstream. However, the discipline of P-limited does not work in the Dianchi Lake. Chen et al. [39] considers TP to be one of main limiting factors in the Dianchi Lake, while Wan et al. [20] argues that TN has replaced TP as the limiting nutrient. Wei et al. [21] believes that the limiting nutrients vary with regard to space in the Dianchi Lake. In view of these contrary opinions, it may be much more difficult to determine the limiting nutrient in the Tanglang River. Nevertheless, in light of the requirements for algae growth, we found that the phytoplankton in the Tanglang River was neither P-limited nor N-limited, as in many other rivers [40], because the concentrations of TP and TN were much greater than the limiting standards 3-6 $\mu \mathrm{g} / \mathrm{L}$ and $100 \mu \mathrm{g} / \mathrm{L}$ [10], respectively. The weak correlations we found between TN, TP and the abundance also supported this point (Table 3). In addition, due to the high concentration $(>60 \mu \mathrm{g} / \mathrm{L})$ [35], $\mathrm{PO}_{4}{ }^{3-}$ had no significant impact on the phytoplankton abundances in the Tanglang River, either.

We also found that the slight change in WT in the space was not responsible for the longitudinal variations of phytoplankton. Although WT is a crucial factor for temporal succession in phytoplankton [30,41], the correlation between WT and the abundance in the Tanglang River revealed that the river temperature did not significantly influence the growth or the loss of algae in the space. High temperatures (above $20{ }^{\circ} \mathrm{C}$ ) favour the growth of Cyanobacteria [29]. The WT in the Tanglang 
River were suitable for Cyanobacteria. In addition to flourishing in higher temperatures more than other competitor algae, Cyanobacteria blooms can also increase local water surface temperatures by light absorption [29]. We found that the WT at T5 without surface assemblages was around $1.2{ }^{\circ} \mathrm{C}$ lower than that at the upper stations in September 2013.

Hydrological and hydrodynamic conditions, including reach lengths, the time of travel and velocities, were among the main regulatory factors responsible for spatial variations in the phytoplankton abundances. The total abundances were significantly negatively related to reach lengths and the TT because Cyanobacteria (mainly Microcystis), originated from the Dianchi Lake, are not adapted to turbulent flow $[6,15,16]$. On the contrary, they tend to be favoured under scenarios of weak mixing, reduced discharge and slow flows [11,42-45]. Hence, Microcystis blooms frequently disturb shallow and relatively stable lakes $[1,29,46]$. In the case, the Dianchi Lake is a permanent source of the Microcystis inoculum for the Tanglang River downstream. However, the importance of this inoculum depends on the turbulence in the rivers downstream. In the slow-flowing rivers, the high inoculum from the lakes will continue to grow $[45,46]$. Otherwise, in the fast-flowing rivers, it will only add to the turbidity [2]. The Tanglang River is a turbid, fast-flowing river (about $0.54 \mathrm{~m} / \mathrm{s}$ of average flow velocity in September and $1.5 \mathrm{~m} / \mathrm{s}$ for the largest flow velocity at T5 in September). The short TT (0.339-1.557 d) was unable to maintain Microcystis in the Tanglang River. According to Reynolds' maximum replicate rate equation [10], the minimum doubling time of Microcystis aeruginosa is about $2.74 \mathrm{~d}$, longer than TT of the Tanglang River. The Microcystis might be washed out rather than grow abundantly. Thus, the abundance of Microcystis decreased downstream in the river. In contrast, the abundance of Bacillariophyta increasing along the river might partly result from the resuspension of meroplanktonic species [47]. In spite of the significant relationships between lengths, TT and the total abundance, the lengths and TT only showed the phenomenon but not explained the spatial variations. It is the flow turbulence, represented as the velocity, explained the variations in phytoplankton abundance. Although the growth rate of Microcystis is slower in comparison to many green algae and diatoms $[10,44,48]$, their buoyancy regulation can compensate for the low growth rate and help them float upwards to gain advantages in relatively stagnant lakes [49]. However, the buoyancy regulation of Microcystis rarely works in turbulent rivers [49] because the turbulent diffusivity enhances the vertical mixing of phytoplankton, which counter the formation of surface Microcystis blooms [50]. If the turbulent diffusivity is high enough, all the algae in rivers would be distributed uniformly in the vertical $[15,49]$. Under the circumstances, the fast-growth-rate algae are advantaged under the equal opportunity to acquire light $[15,48]$ while the slow-growth-rate Cyanobacteria dominances are precluded [6]. Although some lakes, including the Dianchi Lake, are also turbulent $[6,15]$, the turbulent diffusivity is much smaller compared with that in turbulent rivers. Thus, the buoyant Microcystis will still float upwards to have fully photosynthesis and in consequence impede their competitors in those lakes. Li et al. [16] found that flow velocities between 0 and $0.10 \mathrm{~m} / \mathrm{s}$ would promote the rapid growth of phytoplankton. However, the higher flow velocity would inhibit phytoplankton growth. Although some researchers hold the opinion that flow velocities directly suppress the growth of algae [51], our analysis is not fully consistent with them. We suggest that the algae dominance is determined by two functions acting together: self characteristics of algae (buoyant or sinking) and flow turbulence. In the slow-flowing water, the influence of self characteristics outcompetes that of the flow turbulence. Microcystis float upwards while centric 
diatoms and chlorococcales colony green algae sink [29,52]. Accordingly, Microcystis undergo full photosynthesis to form dense surface blooms and then decrease underwater light intensity. However, other heavier and non-mobile algae are precluded. On the contrary, in the fast-flowing water, all the algae distribute uniformly due to high turbulent diffusivity. Hence, Chlorophyta and Bacillariophyta with faster growth rates dominate while Cyanobacteria with slower growth rates are precluded. We have developed a competition model of phytoplankton for light to explain the succession of phytoplankton in different aquatic environment, which will be discussed in detail in the next paper.

Turbidity is another important factor influencing the abundance of phytoplankton in the Tanglang River. It directly reflects light attenuation underwater as a water clarity metric and has a strong relationship with the total suspended solids [53]. Due to the interplay between the turbidity and the algae, the correlations shown in Table 3 were the comprehensive results of following two parts. On the one hand, suspended phytoplankton particles contribute to suspended solids as well as increasing the value of the turbidity. In the Tanglang River, besides a large amount of planktonic algae from the Dianchi Lake, the meroplanktonic diatoms resuspended from the bottom also contributed to the turbidity [52]. On the other hand, increased turbidity might increase light attenuation, which would affect light absorption by different phytoplankton [15]. Since most of the chlorococcales colony green algae are sensitive to low light, including Pediastrum, Coelastrum, and Scenedesmus [28], the low incident light might limit the growth of green algae and diatoms. Hence, the abundances of diatoms and green algae in the Tanglang River did not increase significantly like those in other nutrient-rich rivers $[35,54,55]$. When considering both the positive and the negative effects, the contributions to suspended solids outweighed the suppressed growth of green algae, which led to their weak positive correlation. Nevertheless, low light penetration suppressing the growth of diatoms outweighed their contributions to turbidity, resulting in the negative correlation. In addition, in view of the larger abundance of planktonic algae entering the Tanglang River from the Dianchi Lake upstream in September 2013, the higher self-shading of the phytoplankton might lead to less available penetrated light and, as a consequence, result in the slower increase in the abundances of Chlorophyta and Bacillariophyta in the Tanglang River compared to that in June. In that case, less Chlorophyta and Bacillariophyta would compete for resources with Cyanobacteria in the Tanglang River in September. Accordingly, the decrease rate of Cyanobacteria in September would be slower, which would also account for the less obvious spatial variations in phytoplankton abundances in September 2013.

\section{Conclusions}

(1) Based on environmental variables in Dataset1, the Pudu River was divided into three spatial groups: the Tanglang River which is directly influenced by the highly eutrophic Dianchi Lake upstream (C1), the lower Pudu River which is affected by the river reach upstream (the Tanglang River) and tributaries (C2), and three tributaries which have no eutrophic lakes upstream (C3). The study confirmed that the eutrophic Dianchi Lake upstream made the Tanglang River more heterogeneous in the space and distinguished it obviously from other reaches.

(2) The eutrophic Dianchi Lake upstream contributed the most phytoplankton to the Tanglang River downstream, especially a large amount of Microcystis. Therefore, unlike other rivers, the highest total abundance occurred at the origin of the Tanglang River. However, along the river, the impact of the 
eutrophic Dianchi Lake gradually lessened and the Microcystis in the lower reaches of the Tanglang River were slowly replaced by fluvial algae including chlorococcales green algae and centric diatoms in June. The phytoplankton compositions in the lower reaches of the Tanglang River in June were similar to those found in other nutrient-rich rivers. Our results found that the toxic Microcystis were sustained for a long distance while not disappearing immediately after entering the Tanglang River.

(3) Intensified flow turbulence accounted for the longitudinal variations in the phytoplankton in the river downstream from the eutrophic lake when the nutrients were abundant and water temperature was suitable. In the Tanglang River, it was the lacustrine algae from the Dianchi Lake that comprised most of the algae. Hence, the influencing factors of the total abundance were consistent with those of the lacustrine algae. Strong negative correlations were found between the abundance of Cyanobacteria and the TT $(R=-0.617, P<0.05)$, and the reach lengths $(R=-0.696, P<0.05)$. The spatial variation in the velocity was the most obvious along the Tanglang River. Our results demonstrated that the hydrodynamic condition, represented by the velocity, could be the driving factor accounting for the spatial decrease of Cyanobacteria abundance and the spatial increase of Bacillariophyta and Chlorophyta abundances. Other variables, such as nutrient levels and WT, were not responsible for the spatial variations in phytoplankton abundances in the Tanglang River. Therefore, it is suggested that the flow turbulence could be used to suppress toxic Microcystis and stop them from further contaminating the river environment downstream when the nutrients level is high and WT is suitable.

\section{Acknowledgments}

We acknowledge the financial support of the National Natural Science Foundation of China (No. 51039002 and No. 51279078).

\section{Author Contributions}

Qian $\mathrm{Yu}$ and Zhaowei Liu conducted the field sampling, collected and analyzed the data. Yongcan Chen contributed to the data collection, and supervised the research. Nick van de Giesen and Dejun Zhu provided important advice on the structures of the manuscript and writing. The author and co-authors all contributed to the preparation of the manuscript.

\section{Conflicts of Interest}

The authors declare no conflict of interest.

\section{References}

1. Chen, Y.C.; Yu, Q.; Zhu, D.J.; Liu, Z.W. Possible influencing factors on phytoplankton growth and decay in rivers: Review and perspective. J. Hydroelectr. Eng. 2014, 33, 186-195. (In Chinese)

2. Hilton, J.; O’Hare, M.; Bowes, M.J.; Jones, J.I. How green is my river? A new paradigm of eutrophication in rivers. Sci. Total Environ. 2006, 365, 66-83.

3. Istvánovics, V.; Honti, M.; Vörös, L.; Kozma, Z. Phytoplankton dynamics in relation to connectivity, flow dynamics and resource availability-The case of a large, lowland river, the Hungarian Tisza. Hydrobiologia 2010, 637, 121-141. 
4. Tavernini, S.; Pierobon, E.; Viaroli, P. Physical factors and dissolved reactive silica affect phytoplankton community structure and dynamics in a lowland eutrophic river (Po river, Italy). Hydrobiologia 2011, 669, 213-225.

5. Abonyi, A.; Leitão, M.; Lançon, A.M.; Padisák, J. Phytoplankton functional groups as indicators of human impacts along the River Loire (France). Hydrobiologia 2012, 698, 233-249.

6. Prygiel, J.; Leitão, M. Cyanophycean blooms in the reservoir of Val Joly (northern France) and their development in downstream rivers. Hydrobiologia 1994, 289, 85-96.

7. Paerl, H.W.; Xu, H.; McCarthy, M.J.; Zhu, G.; Qin, B.; Li, Y.; Gardner, W.S. Controlling harmful cyanobacterial blooms in a hyper-eutrophic lake (Lake Taihu, China): The need for a dual nutrient (N \& P) management strategy. Water Res. 2011, 45, 1973-1983.

8. Qin, B.; Zhu, G.; Gao, G.; Zhang, Y.; Li, W.; Paerl, H.W.; Carmichael, W.W. A drinking water crisis in Lake Taihu, China: Linkage to climatic variability and lake management. Environ. Manag. 2010, 45, 105-112.

9. Bahnwart, M.; Hübener, T.; Schubert, H. Downstream changes in phytoplankton composition and biomass in a lowland river-lake system (Warnow River, Germany). Hydrobiologia 1998, 391, 99-111.

10. Reynolds, C.S. Ecology of Phytoplankton; Cambridge University Press: Cambridge, UK, 2006.

11. Allan, J.D.; Castillo, M.M. Stream Ecology: Structure and Function of Running Waters; Springer Science \& Business Media: London, UK, 2007.

12. Hudon, C.; Paquet, S.; Jarry, V. Downstream variations of phytoplankton in the St. Lawrence River (Quebec, Canada). Hydrobiologia 1996, 337, 11-26.

13. Sullivan, B.E.; Prahl, F.G.; Small, L.F.; Covert, P.A. Seasonality of phytoplankton production in the Columbia River: A natural or anthropogenic pattern? Geochim. Cosmochim. Acta 2001, 65, 1125-1139.

14. Sherman, B.S.; Webster, I.T.; Jones, G.J.; Oliver, R.L. Transitions between Auhcoseira and Anabaena dominance in a turbid river weir pool. Limnol. Oceanogr. 1998, 43, 1902-1915.

15. Huisman, J.; Sharples, J.; Stroom, J.M.; Visser, P.M.; Kardinaal, W.E.A.; Verspagen, J.M.; Sommeijer, B. Changes in turbulent mixing shift competition for light between phytoplankton species. Ecology 2004, 85, 2960-2970.

16. Li, F.P.; Zhang, H.P.; Zhu, Y.P.; Xiao, Y.H.; Chen, L. Effect of flow velocity on phytoplankton biomass and composition in a freshwater lake. Sci. Total Environ. 2013, 447, 64-71.

17. Harris, G.P.; Baxter, G. Inter-annual variability in phytoplankton biomass and species composition in a subtropical reservoir. Freshw. Biol. 1996, 35, 545-560.

18. Yang, Y.H.; Zhou, F.; Guo, H.C.; Sheng, H.; Liu, H.; Dao, X.; He, C.J. Analysis of spatial and temporal water pollution patterns in Lake Dianchi using multivariate statistical methods. Environ. Monit. Assess. 2010, 170, 407-416.

19. Nanjing Institute of Geography and Limnology. Environments and Sedimentation of Fault Lakes, Yunnan Province; Science Press: Beijing, China, 1989. (In Chinese)

20. Wan, N.; Song, L.; Wang, R.; Liu, J. The spatio-temporal distribution of algal biomass in Dianchi Lake and its impact factors. Acta Hydrobol. Sin. 2008, 32, 184-188. (In Chinese)

21. Wei, Z.; Zheng, S.F.; Chu, Z.S.; Huang, G.Z.; Jin, X.C. Major growth control factors of Microcystis aeruginosa in Lake Dianchi. Acta Sci. Circumst. 2010, 30, 1472-1478. (In Chinese)

22. Qian, C.Y.; Deng, X.Y.; Xu, J.H.; Wang, R.N.; Zhao, J.C.; Zhu, Y.X. The investigation of the algae in the Tanglangchuan River. J. Yunnan Univ. 1985, 7, 123-137. (In Chinese) 
23. Yu, Q.; Chen, Y.C.; Zhu, D.J.; Liu, Z.W. Pollutant source apportionment of the middle and lower reaches of the Pudu River in Southwest China. In Proceedings of the 35th IAHR World Congress, Chengdu, China, 8-13 September 2013; p. 165.

24. Jin, X.C.; Tu, Q.Y. Criterion of Eutrophication Survey on Lakes; Environmental Science: Beijing, China, 1990. (In Chinese).

25. Hu, H.J.; Wei, Y.X. The Freshwater Algae in China: Systematics, Taxanomy and Ecology; Science Press: Beijing, China, 2006. (In Chinese)

26. Simeonov, V.; Tsakovski, S.; Lavric, T.; Simeonova, P.; Puxbaum, H. Multivariate statistical assessment of air quality: A case study. Microchim. Acta 2004, 148, 293-298.

27. Singh, K.P.; Malik, A.; Sinha, S. Water quality assessment and apportionment of pollution sources of Gomti river (India) using multivariate statistical techniques-A case study. Anal. Chim. Acta 2005, 538, 355-374.

28. Reynolds, C.S.; Huszar, V.; Kruk, C.; Naselli-Flores, L.; Melo, S. Towards a functional classification of the freshwater phytoplankton. J. Plankton. Res. 2002, 24, 417-428.

29. Paerl, H.W.; Huisman, J. Blooms like it hot. Science 2008, 320, 57-58.

30. Ren, Y.; Pei, H.; Hu, W.; Tian, C.; Hao, D.; Wei, J.; Feng, Y. Spatiotemporal distribution pattern of cyanobacteria community and its relationship with the environmental factors in Hongze Lake, China. Environ. Monit. Assess. 2014, 186, 6919-6933.

31. Yu, Q.; Chen, Y.C.; Liu, Z.W.; Zhu, D.J.; Wang, H.R. Longitudinal succession of phytoplankton composition in lake-to-river system. In Proceedings of the 10th International Symposium on Ecohydraulics, Trondheim, Norway, 23-27 June 2014.

32. Becker, V.; Caputo, L.; Ordóñez, J.; Marcé, R.; Armengol, J.; Crossetti, L.O.; Huszar, V.L.M. Driving factors of the phytoplankton functional groups in a deep Mediterranean reservoir. Water Res. 2010, 44, 3345-3354.

33. Reynolds, C.S.; Descy, J.P. The production, biomass and structure of phytoplankton in large rivers. Large Rivers 1996, 10, 161-187.

34. Zhu, M.; Zhu, G.; Zhao, L.; Yao, X.; Zhang, Y.; Gao, G.; Qin, B.Q. Influence of algal bloom degradation on nutrient release at the sediment-water interface in Lake Taihu, China. Environ. Sci. Pollut. Res. 2013, 20, 1803-1811.

35. Bowes, M.J.; Gozzard, E.; Johnson, A.C.; Scarlett, P.M.; Roberts, C.; Read, D.S.; Armstrong, L.K. Spatial and temporal changes in chlorophyll-a concentrations in the River Thames basin, UK: Are phosphorus concentrations beginning to limit phytoplankton biomass? Sci. Total Environ. 2012, 426, 45-55.

36. Reynolds, C.S.; Glaister, M.S. Spatial and temporal changes in phytoplankton abundance in the upper and middle reaches of the River Severn. Large Rivers 1993, 9, 1-22.

37. Bum, B.K.; Pick, F.R. Factors regulating phytoplankton and zooplankton biomass in temperate rivers. Limnol. Oceanogr. 1996, 7, 1572-1577.

38. Lynam, C.P.; Cusack, C.; Stokes, D. A methodology for community-level hypothesis testing applied to detect trends in phytoplankton and fish communities in Irish waters. Estuar. Coast. Shelf Sci. 2010, 87, 451-462. 
39. Chen, Y.C.; Zhang, D.; Tang, L. The spatial and temporal variations of phosphate concentrations and their relationships with algal growth in Lake Dianchi, China. Ecol. Environ. Sci. 2010, 19, 1363-1368. (In Chinese)

40. Devercelli, M.; O'Farrell, I. Factors affecting the structure and maintenance of phytoplankton functional groups in a nutrient rich lowland river. Limnologica 2013, 43, 67-78.

41. Baykal, T.; Açıkgöz, İ.; Udoh, A.U.; Yildiz, K. Seasonal variations in phytoplankton composition and biomass in a small lowland river-lake system (Melen River, Turkey). Turk. J. Biol. 2011, 35, 485-501.

42. Walks, D.J. Persistence of plankton in flowing water. Can. J. Fish. Aquat. Sci. 2007, 64, 1693-1702.

43. Mihaljević, M.; Stević, F. Cyanobacterial blooms in a temperate river-floodplain ecosystem: The importance of hydrological extremes. Aquat. Ecol. 2011, 45, 335-349.

44. Mitrovic, S.M.; Hardwick, L.; Dorani, F. Use of flow management to mitigate cyanobacterial blooms in the Lower Darling River, Australia. J. Plankton Res. 2011, 33, 229-241.

45. Grabowska, M. The role of a eutrophic lowland reservoir in shaping the composition of river phytoplankton. Ecohydrol. Hydrobiol. 2012, 12, 231-242.

46. Grabowska, M.; Mazur-Marzec, H. The effect of cyanobacterial blooms in the Siemianówka Dam Reservoir on the phytoplankton structure in the Narew River. Oceabol. Hydrobiol. Stud. 2011, 40, 19-26.

47. Istvánovics, V.; Honti, M. Efficiency of nutrient management in controlling eutrophication of running waters in the Middle Danube Basin. Hydrobiologia 2012, 686, 55-71.

48. Reynolds, C.S.; Descy, J.P.; Padisák, J. Are phytoplankton dynamics in rivers so different from those in shallow lakes? Hydrobiologia 1994, 289, 1-7.

49. Yu, Q.; Liu, Z.W.; Chen, Y.C.; Zhu, D.J. Modelling daily variation in the vertical distribution of Microcystis. China Environ. Sci. 2015, in press. (In Chinese)

50. Paerl, H.W.; Hall, N.S.; Calandrino, E.S. Controlling harmful cyanobacterial blooms in a world experiencing anthropogenic and climatic-induced changes. Sci. Total Environ. 2011, 409, 1739-1745.

51. Long, T.Y.; Wu, L.; Meng, G.H.; Guo, W.H. Numerical simulation for impacts of hydrodynamic conditions on algae growth in Chongqing Section of Jialing River, China. Ecol. Model. 2011, 222, 112-119.

52. Huisman, J.; Arrayás, M.; Ebert, U.; Sommeijer, B. How do sinking phytoplankton species manage to persist? Am. Nat. 2002, 3, 245-254.

53. Bukaveckas, P.A.; MacDonald, A.; Aufdenkampe, A.; Chick, J.H.; Havel, J.E.; Schultz, R.; Angradi, T.R.; Bolgrien, D.W.; Jicha, T.M.; Taylor, D. Phytoplankton abundance and contributions to suspended particulate matter in the Ohio, Upper Mississippi and Missouri Rivers. Aquat. Sci. 2011, 73, 419-436.

54. Neal, C.; Hilton, J.; Wade, A.J.; Neal, M.; Wickham, H. Chlorophyll-a in the rivers of eastern England. Sci. Total Environ. 2006, 365, 84-104.

55. Istvànovic, V.; Honti, M. Phytoplankton growth in three rivers: The role of meroplankton and the benthic retention hypothesis. Limnol. Oceanogr. 2011, 56, 1439-1452.

(C) 2015 by the authors; licensee MDPI, Basel, Switzerland. This article is an open access article distributed under the terms and conditions of the Creative Commons Attribution license (http://creativecommons.org/licenses/by/4.0/). 